\title{
Thermodynamics of the DNA Repair Process by Endonuclease VIII
}

\author{
O. A. Kladova ${ }^{1}$, N. A. Kuznetsov ${ }^{1,2^{*}}$, O. S. Fedorova ${ }^{1,2, *}$ \\ ${ }^{1}$ Institute of Chemical Biology and Fundamental Medicine, Siberian Branch of the Russian Academy \\ of Sciences, Akad. Lavrentiev Ave. 8, 630090, Novosibirsk, Russia \\ ${ }^{2}$ Department of Natural Sciences, Novosibirsk State University, Pirogova Str. 2, 630090, \\ Novosibirsk Russia. \\ *E-mail: fedorova@niboch.nsc.ru,nikita.kuznetsov@niboch.nsc.ru \\ Received October 12, 2018; in final form January 21, 2019 \\ Copyright @ 2019 National Research University Higher School of Economics. This is an open access article distributed under the Creative Commons \\ Attribution License, which permits unrestricted use, distribution, and reproduction in any medium, provided the original work is properly cited.
}

\begin{abstract}
In the present work, a thermodynamic analysis of the interaction between endonuclease VIII (Endo VIII) and model DNA substrates containing damaged nucleotides, such as 5,6-dihydrouridine and 2-hydroxymethyl-3-hydroxytetrahydrofuran (F-site), was performed. The changes in the fluorescence intensity of the 1,3-diaza-2-oxophenoxazine $\left(\mathrm{tC}^{\circ}\right)$ residue located in the complementary chain opposite to the specific site were recorded in the course of the enzyme-substrate interaction. The kinetics was analyzed by the stopped-flow method at different temperatures. The changes of standard Gibbs free energy, enthalpy, and entropy of sequential steps of DNA substrate binding, as well as activation enthalpy and entropy for the transition complex formation of the catalytic stage, were calculated. The comparison of the kinetic and thermodynamic data characterizing the conformational transitions of enzyme and DNA in the course of their interaction made it possible to specify the nature of the molecular processes occurring at the stages of substrate binding, recognition of the damaged base, and its removal from DNA.
\end{abstract}

KEYWORDS thermodynamics, pre-steady-state kinetics, kinetic mechanism, DNA glycosylase.

ABBREVIATIONS Endo VIII - endonuclease VIII; AP-site - apurinic/apyrimidinic site; F-site - (3-hydroxytetrahydrofuran-2-yl) methyl phosphate; DHU - 5,6-dihydrouridine.

\section{INTRODUCTION}

Endonuclease VIII (Endo VIII or Nei) is one of the key DNA glycosylases in Escherichia coli responsible for the elimination of a wide range of oxidized and reduced pyrimidine bases $[1,2]$. The products of oxidation/ reduction of pyrimidine bases in DNA are thymine glycol, 5,6-dihydrothymine, 5,6-dihydrouracil, urea, 5-formyluracil, 5-hydroxymethyluracil, 5-hydroxycytosine, 5-hydroxyuracil, uracil glycol, etc. Endo VIII catalyzes the hydrolysis of the $\mathrm{N}$-glycosidic bond of a damaged base (N-glycosylase activity) with subsequent $\beta$-elimination of the 3' and 5' phosphate groups of the apurinic/apyrimidinic site (AP lyase activity), resulting in the formation of a single-strand break in DNA (Fig. 1) [3, 4].

$\mathrm{X}$-ray structural analysis of the free enzyme and its complex with DNA showed that the interaction of Endo VIII with DNA leads to conformational changes both in the protein and substrate molecules [5, 6]. In the enzyme-substrate complex, the ribose-phosphate backbone of DNA is bent at approximately $45^{\circ}$, the damaged base is extruded from the DNA helix and inserted in the active center of the enzyme, while the
Gln69, Leu70, and Tyr71 residues are positioned into the resulting cavity (Fig. 2). Such changes in the structure of interacting molecules lead to the formation of specific contacts, providing highly efficient recognition and binding of damaged DNA nucleotides.

Previously, we performed the kinetic analysis of conformational changes in Endo VIII and the DNA substrate during their interaction using the stoppedflow method with registration of the changes in the fluorescence intensity of tryptophan residues in the enzyme structure [7] and a number of fluorescent analogues of heterocyclic bases in DNA [8] located on the 3' side or complementary to the damaged nucleotide. Later [9], we used the strategy of site-directed

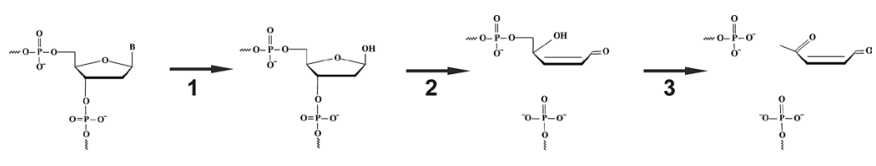

Fig. 1. Chemical steps in Endo VIII catalysis. Step 1, DHU base removal; step 2, $\beta$-elimination of the 3'-phosphate; step $3, \beta$-elimination of the 5 '-phosphate. 


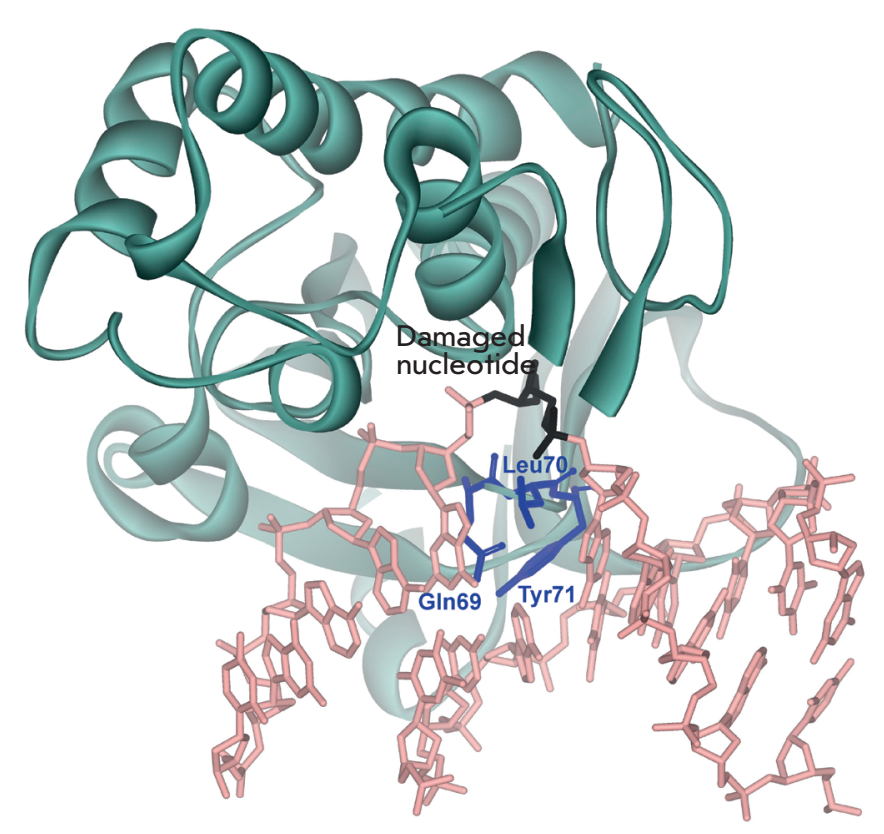

Fig. 2. The structure of Endo VIII complexed with DNA containing an AP-site (Protein Data Bank code 1K3W) [6]

mutagenesis to clarify the nature of the sequential stages of DNA binding. All the kinetic data characterizing conformational changes in the enzyme and DNA substrates, as well as the results of the mutational analysis, allowed us to propose a molecular kinetic mechanism for the recognition of a damaged nucleotide by the Endo VIII enzyme (Scheme 1). Stage 1 corresponds to a rapid initial binding of DNA and formation of a non-specific enzyme-substrate complex in which the $\mathrm{N}$ - and $\mathrm{C}$-domains of the enzyme are in a closed position. At this stage, the Leu70 residue is wedged into the DNA duplex, which is the key stage of recognition of the damaged DNA region. Stage 2 involves the bending of the double helix at the damaged base site, the eversion of 5,6-dihydrouracil from the duplex, and the incorporation of the Tyr71 residue in the DNA helix, required for the stabilization of the inverted conformation of the damaged base. In stage 3 , the conformation of the active center is adjusted in order to achieve a catalytically competent state. The Tyr71 residue is also utilized in stage 3 . In this stage, contacts are formed between Phe121 and the ribose-phosphate backbone of DNA. The formation of the catalytic complex leads to the hydrolysis of the Nglycosidic bond, followed by the $\beta$-elimination of the 3 ' and 5' phosphate groups (stage 4). The final stage of the enzymatic cycle is the dissociation of the enzymeproduct complex (stage 5).
Scheme 1. Kinetic mechanism of interaction between Endo VIII and DHU substrate

$$
\begin{aligned}
& \mathrm{E}+\mathrm{DHU} \underset{k_{-1}}{\stackrel{k_{1}}{\rightleftarrows}}(\mathrm{E} \cdot \mathrm{DHU})_{1} \underset{k_{-2}}{\stackrel{k_{2}}{\rightleftarrows}}(\mathrm{E} \cdot \mathrm{DHU})_{2} \underset{k_{-3}}{\stackrel{2}{\rightleftarrows}}
\end{aligned}
$$

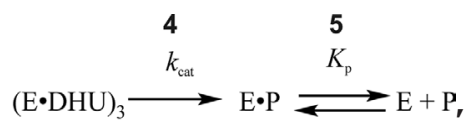

where $\mathrm{E}$ is EndoVIII, DHU is DHU substrate, $(\mathrm{E} \cdot \mathrm{DHU})_{\mathrm{n}}$ are enzyme-substrate complexes, $E \cdot P$ is a complex of the enzyme with the product $\mathrm{P}$, and $k_{\mathrm{i}}$ and $k_{-i}$ are rate constants for $i^{\text {th }}$ step.

In order to confirm the kinetic mechanism proposed (Scheme 1) and specify the nature of individual stages, we determined the thermodynamic parameters of the fast stages of the interaction between Endo VIII and DNA and the specific recognition of a damaged nucleotide based on the kinetic parameters obtained at different temperatures.

\section{EXPERIMENTAL}

Oligodeoxyribonucleotides

Oligonucleotides were purified by HPLC on an ion exchange column (PRP-X500 Hamilton Company $3.9 \times 300 \mathrm{~mm}$; particle size, $12-30 \mu \mathrm{m})$, followed by reverse phase chromatography (Nucleoprep 100-20 $\mathrm{C}_{18}$ $10 \times 250 \mathrm{~mm}$, Macherey-Nagel, Germany). The purity of the oligonucleotides was verified by denaturing electrophoresis in a $20 \%$ polyacrylamide gel (PAAG). The concentration of oligonucleotides was determined based on the optical density of solutions at a wavelength of $260 \mathrm{~nm}$ in electronic absorption spectra and molar extinction coefficients calculated using the nearest neighbor method [10].

DNA duplexes of $17 \mathrm{bp}$ containing 1,3-diaza-2-oxophenoxazine fluorophore $\left(\mathrm{tC}^{\mathrm{O}}\right)$, instead of a cytosine residue in the complementary chain opposite the specific site, were used as DNA substrates (Table 1). The specific sites were the 5,6-dihydrouridine residue, which served as the damaged base, and an F-site, which is an analog of an intermediate product of the

Table 1. Structure of the DNA-duplexes used in this study

\begin{tabular}{|c|c|}
\hline Name & DNA-duplex \\
\hline DHU-DNA, $X=$ DHU & \\
F-DNA, $X=$ F-site & 5'-TCTCTCTCXCCTTCCTT-3' \\
G-DNA, $X=$ G & ${\text { 3'-AGAGAGAG }\left(\text { tC }^{\circ}\right) \text { GGAAGGAA-5' }}$ \\
\hline
\end{tabular}


enzymatic reaction; i.e., the apurinic/apyrimidinic site (AP site). A duplex containing no modified nucleotides was used as intact DNA.

\section{Endonuclease VIII}

Endo VIII was isolated from E. coli Rosetta II (DE3) cells transformed with a pET-24b plasmid carrying the enzyme gene. The $E$. coli Rosetta II (DE3) cells were cultivated in a LB medium $(1 \mathrm{~L})$ containing $50 \mu \mathrm{g} / \mathrm{ml}$ ampicillin at $37^{\circ} \mathrm{C}$ until it reached an optical density of $0.6-0.7$ at a $600-\mathrm{nm}$ wavelength. After this, the temperature was decreased to $30^{\circ} \mathrm{C}$ and transcription was induced by addition of isopropyl$\beta$ - $D$-thiogalactopyranoside to a final concentration of $0.2 \mathrm{mM}$. After induction, the cell culture was incubated for $8 \mathrm{~h}$. Next, the cells were precipitated by centrifugation (10 min, 12,000 rpm) and the cell suspension was prepared in $30 \mathrm{ml}$ of a buffer solution $(20 \mathrm{mM}$ HEPES-NaOH, pH 7.8; $40 \mathrm{mM} \mathrm{NaCl}$ ). The cells were lysed using a French press (French Press Cell, Thermo Fisher Scientific, USA). All subsequent procedures were performed at $4^{\circ} \mathrm{C}$. The cell lysate was centrifuged (40 min at 30,000 rpm); the supernatant was loaded onto column I (Q-Sepharose Fast Flow, Amersham Biosciences, Sweden) and washed with the buffer solution (20 mM HEPES-NaOH, $\mathrm{pH} 7.8 ; 40 \mathrm{mM} \mathrm{NaCl}$ ). Protein-containing fractions were collected and loaded onto column II (HiTrap-Heparin ${ }^{\mathrm{TM}}$, Amersham Biosciences, Sweden). Chromatography was performed in a linear gradient of $40 \rightarrow 1500 \mathrm{mM} \mathrm{NaCl}$, and the optical density of the solution was measured at $280 \mathrm{~nm}$. The degree of protein purity was determined by gel electrophoresis. Fractions containing the Endo VIII protein were dialyzed in $20 \mathrm{mM}$ HEPES-NaOH buffer, $\mathrm{pH}$ 7.5, $1 \mathrm{mM}$ EDTA, $1 \mathrm{mM}$ dithiothreitol, $250 \mathrm{mM} \mathrm{NaCl}$, $50 \%$ glycerol and stored at $-20^{\circ} \mathrm{C}$. Enzyme concentration was calculated based on the optical density of the protein at $280 \mathrm{~nm}$ and a molar extinction coefficient of $32680 \mathrm{M}^{-1} \times \mathrm{cm}^{-1}[11]$.

Kinetic studies using the stopped-flow method Kinetic curves were obtained based on the changes in $\mathrm{tC}^{\mathrm{O}}$ fluorescence intensity on a stopped-flow spectrometer SX.20 (Applied Photophysics, Great Britain). The $\mathrm{tC}^{\mathrm{O}}$ fluorescence excitation wavelength was $360 \mathrm{~nm}$. Fluorescence was recorded at wavelengths greater than $395 \mathrm{~nm}$ (Schott filter GG 395). The instrument dead time was $1.4 \mathrm{~ms}$; the maximum signal acquisition time was $500 \mathrm{~s}$. All experiments were performed in a buffer solution of $50 \mathrm{mM}$ Tris- $\mathrm{HCl}, \mathrm{pH}$ 7.5, $50 \mathrm{mM} \mathrm{KCl}, 1 \mathrm{mM}$ dithiothreitol, $1 \mathrm{mM}$ EDTA, $7 \%$ glycerol at a temperature range of 5 to $25^{\circ} \mathrm{C}$. Each kinetic curve was averaged over at least three experimental curves.

\section{Analysis of kinetic curves}

In order to calculate the rate constants for conformational transitions, a set of kinetic curves was obtained for different concentrations of the enzyme at different temperatures. The fluorescence intensity of $\mathrm{tC}^{\mathrm{O}}$ was recorded under conditions close to one enzyme turnover; i.e., at enzyme and substrate concentrations of the same magnitude. To determine the minimum kinetic scheme describing the interaction of the enzyme with a substrate and to calculate rate constants for all elementary reactions corresponding to this scheme, the DynaFit software (BioKin, USA) was used [12]. Quantitative processing of the results was performed by optimization of the values of the parameters comprising the kinetic schemes as previously described [13-16].

Using the values obtained for the rate constants of direct and reverse reactions for individual reversible stages, we calculated the equilibrium constants $K_{\mathrm{i}}$ for these stages $\left(K_{\mathrm{i}}=k_{\mathrm{i}} / k_{-\mathrm{i}}\right.$, where $i$ is the stage number) at different temperatures. The standard thermodynamic parameters of the $i^{\text {th }}$ equilibrium stage were determined using the Van't Hoff equation (1) [17, 18] as previously described [19-23].

$$
\ln \left(K_{\mathrm{i}}\right)=-\Delta \mathrm{G}_{\mathrm{i}}{ }^{\circ} / \mathrm{RT}=-\Delta \mathrm{H}_{\mathrm{i}}{ }^{\circ} / \mathrm{RT}+\Delta \mathrm{S}_{\mathrm{i}}{ }^{\circ} / \mathrm{R} .
$$

Analysis of the temperature dependence of the $k_{\text {cat }}$ rate constant using the Eyring equation (2) allowed us to calculate the standard activation enthalpy $\left(\Delta \mathrm{H}^{\circ, \dot{*}}\right)$ and the standard activation entropy $\left(\Delta \mathbf{S}^{\mathrm{o}, \text { ₹}}\right)$ of the transition state [17].

$$
\ln \left(k_{\text {cat }} / \mathrm{T}\right)=\ln \left(k_{\mathrm{B}} / h\right)+\left(\Delta \mathrm{S}^{\mathrm{o}, \ddagger} / \mathrm{R}\right)-\left(\Delta \mathrm{H}^{\mathrm{o}, \ddagger} / \mathrm{RT}\right),
$$

where $k_{\mathrm{B}}$ and $h$ are the Boltzmann and Planck constants, respectively; $R$ is the universal gas constant; $T$ is the absolute temperature in Kelvin degrees; and $k_{\text {cat }}$ is the rate constant for the irreversible catalytic stage.

\section{RESULTS AND DISCUSSION}

Interaction between Endo VIII and intact G-DNA Figure $3 \mathrm{~A}$ presents the kinetic curves for the interaction between Endo VIII and the DNA duplex G-DNA containing a guanine residue complementary to the fluorophore group $\mathrm{tC}^{\mathrm{O}}$ obtained by registration of the changes in the $\mathrm{tC}^{\mathrm{O}}$ fluorescence intensity during the reaction. One phase of growth in the fluorescence intensity, which reaches a plateau, can be noted on the kinetic curves. When increasing the temperature, the time necessary to reach the plateau shifts from $\sim 30 \mathrm{~ms}$ at $5^{\circ} \mathrm{C}$ to $\sim 20 \mathrm{~ms}$ at $25^{\circ} \mathrm{C}$ (Fig. $3 \mathrm{C}$ ). The kinetic curves obtained are satisfactorily described by single-stage 

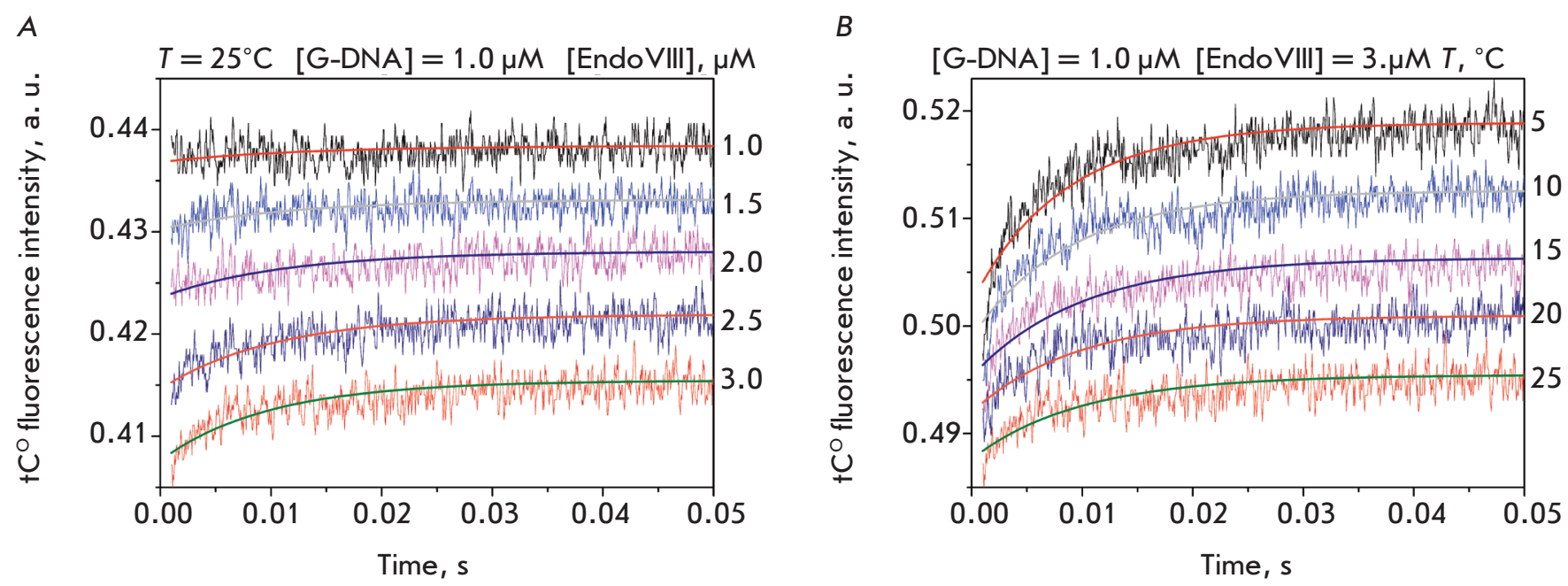

Fig. 3. Interaction of Endo VIII with intact G-DNA. A - Changes in the $t C^{\circ}$ fluorescence intensity. Jagged traces represent experimental data; smooth curves are the results of fitting to Scheme 2. [G-DNA] $=1.0 \mu M$, concentrations of Endo VIII $(1.0-3.0 \mu M)$ are shown on the right side of the plot. $B-$ Changes in the $t C^{\circ}$ fluorescence intensity of the interaction of Endo VIII with G-DNA at different temperatures ([Endo VIII] $=3.0 \mu M$, [G-DNA] $=1.0 \mu M$ )

Table 2. Rate and equilibrium constants of the interaction of Endo VIII with intact G-DNA

\begin{tabular}{|c|c|c|c|c|c|}
\hline \multirow{2}{*}{ Constants } & \multicolumn{5}{|c|}{ Temperature, ${ }^{\circ} \mathrm{C}$} \\
\hline & 5 & 10 & 15 & 20 & 25 \\
\hline$k_{1}, \mathrm{M}^{-1} \mathrm{~s}^{-1}$ & $(16 \pm 7) \times 10^{6}$ & $(16 \pm 8) \times 10^{6}$ & $(15 \pm 9) \times 10^{6}$ & $(14 \pm 6) \times 10^{6}$ & $(9 \pm 2) \times 10^{6}$ \\
\hline$k_{-1}, \mathrm{~s}^{-1}$ & $50 \pm 30$ & $60 \pm 40$ & $50 \pm 20$ & $60 \pm 40$ & $40 \pm 10$ \\
\hline$K_{1}, \mathrm{M}^{-1}$ & $(0.31 \pm 0.21) \times 10^{6}$ & $(0.26 \pm 0.21) \times 10^{6}$ & $(0.29 \pm 0.20) \times 10^{6}$ & $(0.25 \pm 0.18) \times 10^{6}$ & $(0.19 \pm 0.08) \times 10^{6}$ \\
\hline
\end{tabular}

equilibrium kinetic $S$ cheme 2 . The rate constants characterizing this stage are presented in Table 2.

Scheme 2. Kinetic mechanism of interaction between Endo VIII and intact DNA

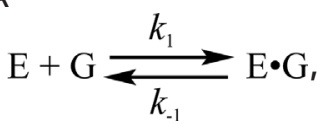

where $E$ is EndoVIII, $G$ is intact DNA, E . $G$ is the enzyme-DNA complex, and $k_{1}$ and $k_{-1}$ are the rate constants.

Interaction of Endo VIII with AP site analog F-DNA Interaction between Endo VIII and the AP site in DNA has been studied using a DNA duplex containing a noncleavable analog of the AP site (tetrahydrofuran $\mathrm{F}$ derivative) and the fluorophore group tC $\mathrm{C}^{\mathrm{O}}$ opposite a damaged nucleotide in the complementary chain (Fig. 4). Two phases of $\mathrm{tC}^{\mathrm{O}}$ fluorescence intensity growth can be distinguished on the kinetic curves presented in Fig. 4. The first phase of growth takes place in the same time range (up to $\sim 20 \mathrm{~ms}$ ) as in the case of interaction with intact G-DNA. The same conformational transformation caused by binding to Endo VIII is likely to occur in the structure of DNA duplexes containing both the $\mathrm{G}$ and $\mathrm{F}$ sites at the initial time. However, there is a second stage of $\mathrm{tC}^{\mathrm{O}}$ fluorescence intensity growth for the $\mathrm{F}$ ligand which is completed by the 1 st second at all temperatures (Fig. 4). In addition, the changes in the kinetic curves of the interaction between an F-containing DNA and Endo VIII have a higher amplitude than in the case of G-DNA, suggesting both greater efficiency of complex formation between the enzyme and DNA and more significant conformational rearrangements in the structure of the DNA duplex containing the F-site.

Processing of the data obtained resulted in the determination of a minimal kinetic reaction scheme which included two reversible stages of the formation of the enzyme-substrate complex (Scheme 3). The reaction rate constants and equilibrium constants calculated are presented in Table 3. 

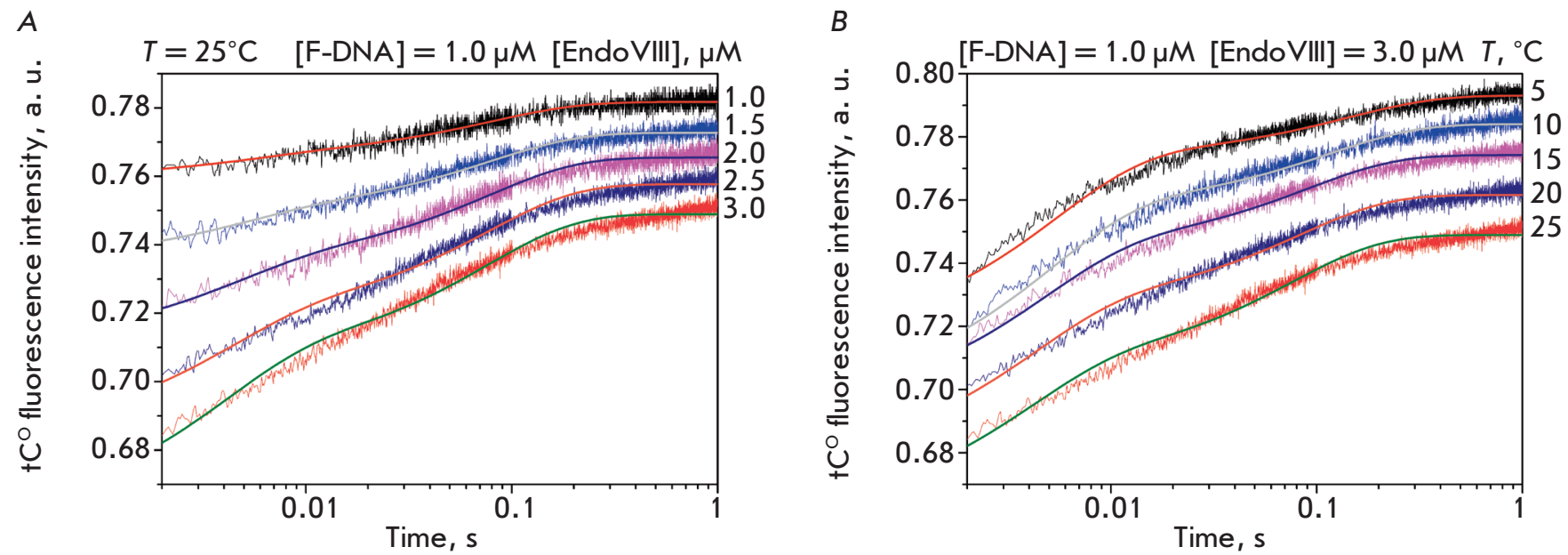

Fig. 4. Interaction of Endo VIII with F-DNA. A - Changes in the $\mathrm{CC}^{\circ}$ fluorescence intensity. Jagged traces represent experimental data; smooth curves are the results of fitting to Scheme 3. [F-DNA] $=1.0 \mu \mathrm{M}$, concentrations of Endo VIII $(1.0-3.0 \mu \mathrm{M})$ are shown on the right side of the plot. $B$ - Changes in the $+C^{\circ}$ fluorescence intensity of the interaction of Endo VIII with F-DNA at different temperatures ([Endo VIII] $=3.0 \mu \mathrm{M},[\mathrm{F}-\mathrm{DNA}]=1.0 \mu \mathrm{M}$ )

Table 3. Rate and equilibrium constants of the interaction of Endo VIII with F-DNA

\begin{tabular}{|c|c|c|c|c|c|}
\hline \multirow{2}{*}{ Constants } & \multicolumn{5}{|c|}{ Temperature, ${ }^{\circ} \mathrm{C}$} \\
\cline { 2 - 5 } & 5 & 10 & 15 & 20 & 25 \\
\hline$k_{1}, \mathrm{M}^{-1} \mathrm{~s}^{-1}$ & $(35 \pm 9) \times 10^{6}$ & $(35 \pm 5) \times 10^{6}$ & $(37 \pm 5) \times 10^{6}$ & $(39 \pm 5) \times 10^{6}$ & $(40 \pm 8) \times 10^{6}$ \\
\hline$k_{-1}, \mathrm{~s}^{-1}$ & $89 \pm 22$ & $99 \pm 18$ & $109 \pm 28$ & $129 \pm 43$ & $144 \pm 46$ \\
\hline$K_{1}, \mathrm{M}^{-1}$ & $(0.4 \pm 0.1) \times 10^{6}$ & $(0.35 \pm 0.08) \times 10^{6}$ & $(0.3 \pm 0.1) \times 10^{6}$ & $(0.3 \pm 0.1) \times 10^{6}$ & $(0.3 \pm 0.1) \times 10^{6}$ \\
\hline$k_{2}, \mathrm{~s}^{-1}$ & $0.3 \pm 0.1$ & $0.9 \pm 0.3$ & $1.4 \pm 0.2$ & $3 \pm 1$ & $3 \pm 1$ \\
\hline$k_{-2}, \mathrm{~s}^{-1}$ & $7 \pm 2$ & $8 \pm 1$ & $10 \pm 1$ & $11 \pm 1$ & $12 \pm 1$ \\
\hline$K_{2}$ & $0.04 \pm 0.02$ & $0.11 \pm 0.03$ & $0.13 \pm 0.02$ & $0.24 \pm 0.09$ & $0.26 \pm 0.08$ \\
\hline
\end{tabular}

Scheme 3. Kinetic mechanism of interaction between Endo VIII and F-DNA

$$
\mathrm{E}+\mathrm{F} \underset{k_{-1}}{\stackrel{k_{1}}{\rightleftarrows}}(\mathrm{E} \cdot \mathrm{F})_{1} \underset{k_{-2}}{\stackrel{k_{2}}{\rightleftarrows}}(\mathrm{E} \cdot \mathrm{F})_{2},
$$

where $E$ is EndoVIII, $F$ is F-DNA, $(E \cdot F)_{n}$ are enzyme-substrate complexes, and $k i$ and $k_{-i}$ are the rate constants for the $i^{\text {th }}$ step.

\section{Interaction of Endo VIII with DHU-DNA}

Figure $5 \mathrm{~A}$ presents the kinetic curves obtained for the interaction between Endo VIII and the DNA substrate containing 5,6-dihydrouridine (DHU-DNA). The curves are even more complicated than those obtained for G$\mathrm{DNA}$ and F-DNA. Similar changes in the $\mathrm{tC}^{\circ}$ fluorescence intensity can be noted for all concentration series at different temperatures $\left(5-25^{\circ} \mathrm{C}\right)$ (Fig. 5B).

Analysis of the kinetic curves registered at $5-15^{\circ} \mathrm{C}$ demonstrated a rapid growth in the $\mathrm{tC}^{\mathrm{O}}$ fluorescence intensity at the initial region (up to $10 \mathrm{~ms}$ ) (phase 1).
At increased temperatures, this change in the fluorescence intensity disappears almost completely. Following the 1st growth phase, further increase in the fluorescence signal can be identified at all temperatures. The duration of the 2nd phase of growth decreased with an increase in the temperature from $\sim 300 \mathrm{~ms}$ at $5^{\circ} \mathrm{C}$ to $\sim 80 \mathrm{~ms}$ at $25^{\circ} \mathrm{C}$.

It is known that the changes in the DNA helix structure, the extrusion of the damaged nucleotide, and the incorporation of a series of amino acid residues of the enzyme into the DNA helix occur when Endo VII binds to DNA [6]. Endo VIII forms an extensive network of contacts with DNA. However, the contacts formed by the amino acid residues of the triad Gln69-Leu70Tyr71 play the most important role in the recognition of a damaged nucleotide.

For all the curves obtained, one can distinguish the phase of drop in the $\mathrm{tC}^{\mathrm{O}}$ fluorescence intensity (phase 3 ). This phase has a pronounced temperature dependence. For instance, the phase of drop in the $\mathrm{tC}^{\circ}$ fluo- 

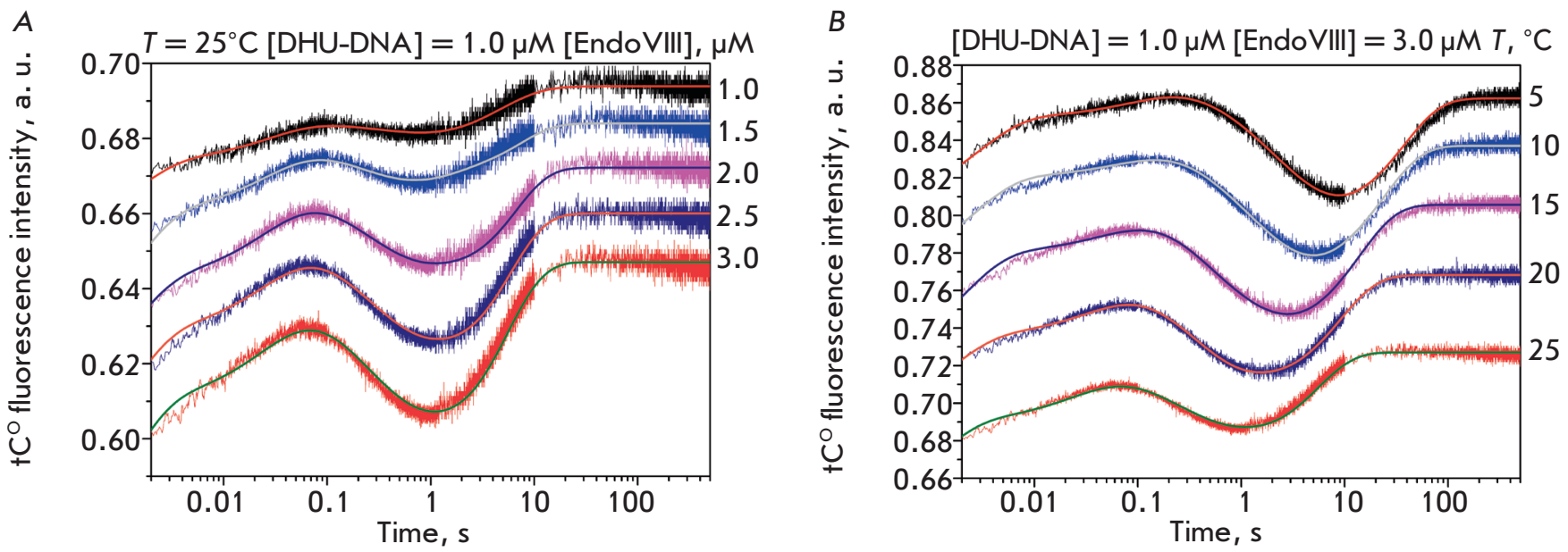

Fig. 5. Interaction of Endo VIII with DHU-DNA. A - Changes in the $t C^{\circ}$ fluorescence intensity. Jagged traces represent experimental data; smooth curves are the results of fitting to Scheme 1. [DHU-DNA] $=1.0 \mu \mathrm{M}$, concentrations of Endo $\mathrm{VIII}(1.0-3.0 \mu \mathrm{M})$ are shown on the right side of the plot. $B$ - Changes in the $+C^{\circ}$ fluorescence intensity of the interaction of Endo VIII with DHU-DNA at different temperatures ([Endo VIII] $=3.0 \mu \mathrm{M},[\mathrm{DHU}-\mathrm{DNA}]=1.0 \mu \mathrm{M}$ )

Table 4. Rate and equilibrium constants of the interaction of Endo VIII with DHU-DNA

\begin{tabular}{|c|c|c|c|c|c|}
\hline \multirow{2}{*}{ Constants } & \multicolumn{5}{|c|}{ Temperature, ${ }^{\circ} \mathrm{C}$} \\
\cline { 2 - 6 } & 5 & 10 & 15 & 20 & 25 \\
\hline$k_{1}, \mathrm{M}^{-1} \mathrm{~s}^{-1}$ & $35 \pm 7$ & $40 \pm 6$ & $45 \pm 7$ & $61 \pm 4$ & $80 \pm 13$ \\
\hline$k_{-1}, \mathrm{~s}^{-1}$ & $230 \pm 30$ & $270 \pm 40$ & $320 \pm 10$ & $440 \pm 70$ & $580 \pm 50$ \\
\hline$K_{1}, \mathrm{M}^{-1}$ & $(0.149 \pm 0.038) \times 10^{6}$ & $(0.147 \pm 0.032) \times 10^{6}$ & $(0.140 \pm 0.023) \times 10^{6}$ & $(0.140 \pm 0.025) \times 10^{6}$ & $(0.138 \pm 0.027) \times 10^{6}$ \\
\hline$k_{2}, \mathrm{~s}^{-1}$ & $1.0 \pm 0.2$ & $1.7 \pm 0.1$ & $2.6 \pm 0.4$ & $3.6 \pm 0.6$ & $4 \pm 1$ \\
\hline$k_{-2}, \mathrm{~s}^{-1}$ & $0.34 \pm 0.08$ & $0.62 \pm 0.03$ & $0.9 \pm 0.7$ & $1.2 \pm 1$ & $1.3 \pm 0.3$ \\
\hline$K_{2}$ & $2.72 \pm 0.94$ & $2.76 \pm 0.24$ & $2.83 \pm 2$ & $3.0 \pm 2.7$ & $3.0 \pm 1$ \\
\hline$k_{3}, \mathrm{~s}^{-1}$ & $6.5 \pm 1.4$ & $8.1 \pm 0.6$ & $12 \pm 2$ & $18 \pm 4$ & $29 \pm 3$ \\
\hline$k_{-3}, \mathrm{~s}^{-1}$ & $1.6 \pm 0.3$ & $1.9 \pm 0.6$ & $2.5 \pm 0.6$ & $3 \pm 1$ & $4.4 \pm 1.6$ \\
\hline$K_{3}$ & $4 \pm 1$ & $4.3 \pm 1.4$ & $4.6 \pm 1.3$ & $5.3 \pm 1.9$ & $6.6 \pm 2.5$ \\
\hline$k_{\text {cat }} \mathrm{s}^{-1}$ & $0.06 \pm 0.02$ & $0.09 \pm 0.05$ & $0.15 \pm 0.05$ & $0.22 \pm 0.08$ & $0.34 \pm 0.02$ \\
\hline$K_{5}, \mathrm{M}^{-1}$ & $(0.06 \pm 0.03) \times 10^{6}$ & $(0.047 \pm 0.019) \times 10^{6}$ & $(0.042 \pm 0.016) \times 10^{6}$ & $(0.038 \pm 0.010) \times 10^{6}$ & $(0.034 \pm 0.18) \times 10^{6}$ \\
\hline
\end{tabular}

rescence intensity lasts up to $10 \mathrm{~s}$ at $5^{\circ} \mathrm{C}$ and only up to $1 \mathrm{~s}$ at $25^{\circ} \mathrm{C}$. Such a change corresponds to another stage occurring during the formation of the enzyme-substrate complex. Since a decrease in the $\mathrm{tC}^{\mathrm{O}}$ fluorescence intensity indicates a change in the microenvironment of the fluorophore group, one can assume the adjustment of the enzyme and DNA conformations to take place at this moment to form a catalytically competent enzyme-substrate complex.

An increase in the fluorescence signal (phase 4), followed by the reaching of a plateau, (phase 5) is observed immediately after a drop in $\mathrm{tC}^{\mathrm{O}}$ fluorescence intensity. It is most likely that the fourth stage of change in the fluorescence intensity reflects the catalytic stages in the enzymatic process, while the fifth stage represents the dissociation of the enzyme complex from the reaction product.

Thus, a total of five phases of changes in the $\mathrm{tC}^{\circ}$ fluorescence intensity have been identified in the kinetic curves of interaction between endonuclease VII and a DNA substrate containing 5,6-dihydrouridine. A minimal kinetic scheme describing the kinetic curves includes three reversible stages that lead to the formation of an enzyme-substrate complex, one irreversible stage, which can be attributed to the catalytic reaction stage, and one reversible stage of the enzyme-product complex dissociation (Scheme 1). The calculated values of the rate constants for individual stages and equilibrium constants are presented in Table 4. 

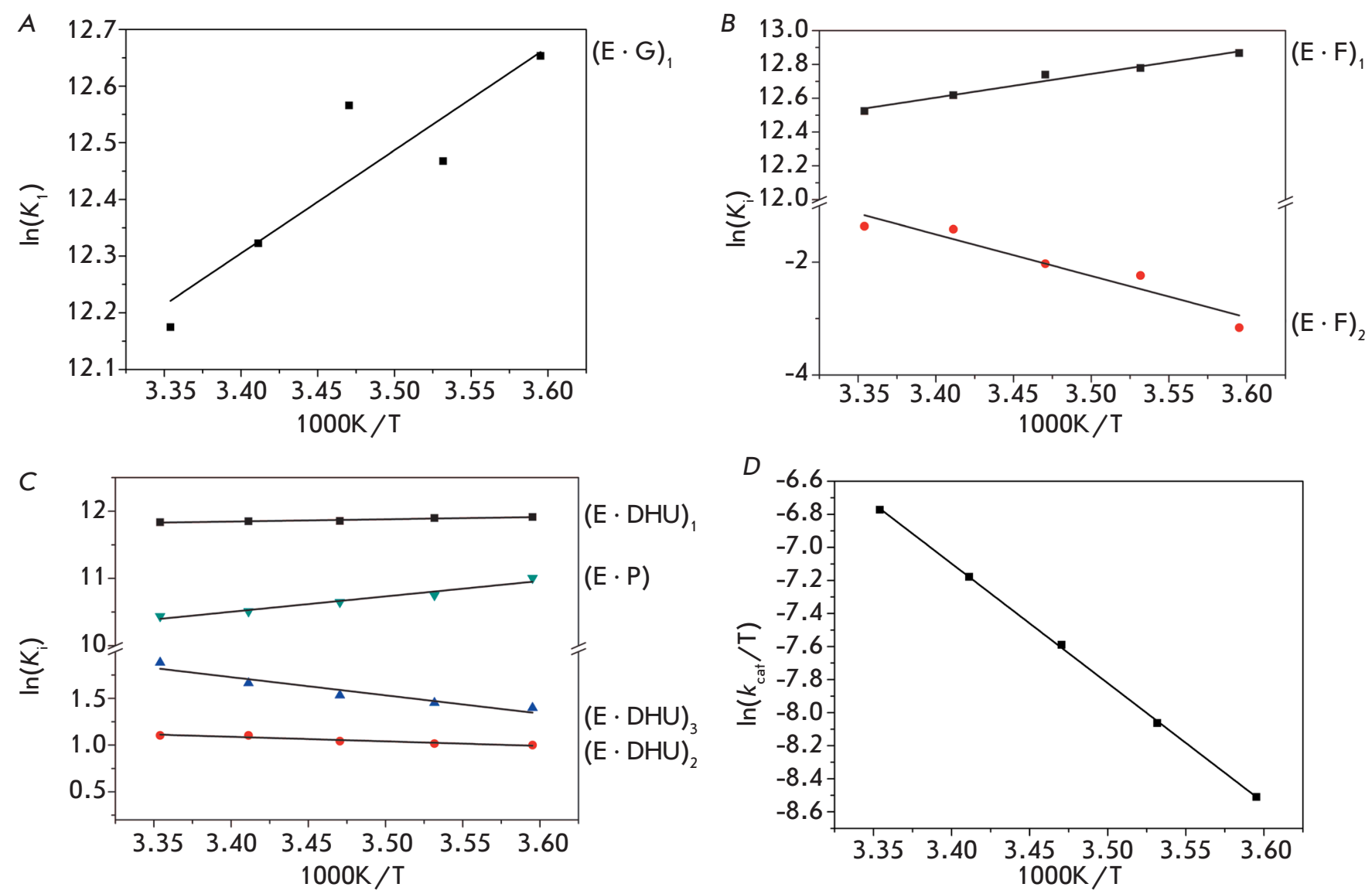

Fig. 6. Van't Hoff analysis of the temperature dependence of Ki for G-DNA (A), F-DNA (B), and DHU-DNA (C). (D) Analysis of the temperature dependence of $\ln \left(k_{\text {cat }} / T\right)$ characterizing the transition state of the catalytic step for DHU-DNA

Thermodynamic parameters of the interaction between Endo VIII and DNA substrates

The rate constants for the individual stages of the interaction between Endo VIII and all DNA substrates at different temperatures were used to calculate equilibrium constants for these stages $\left(K_{\mathrm{i}}\right)$. The equilibrium constants of individual stages were used for obtaining the dependence of $\ln \left(K_{\mathrm{i}}\right)$ on $1 / \mathrm{T}$ (van't Hoff equation (1)) (Fig. 6). The dependence of $\ln \left(k_{\text {cat }} / \mathrm{T}\right)$ on $1 / \mathrm{T}$ (Eyring equation (2)) that characterizes the irreversible catalytic reaction in the case of the DHU substrate was also obtained. All dependencies had a linear form and allowed us to calculate the changes in enthalpy and entropy for reversible stages $\left(\Delta \mathrm{H}_{\mathrm{i}}^{\circ}\right.$ и $\left.\Delta \mathrm{S}_{\mathrm{i}}{ }^{\circ}\right)$ and the transition state of the catalytic stage $\left(\Delta \mathrm{H}^{\circ, \sharp}\right.$ и $\left.\Delta \mathbf{S}^{\circ, \sharp}\right)$ (Table 5).

When analyzing the thermodynamic parameters of the interaction between Endo VIII and DNA substrates, we succeeded in identifying some common features. For instance, primary binding of the enzyme to all the DNA substrates used in the study is accompanied by a slight decrease in enthalpy and an increase in entropy. It leads to a negative value of the change in the Gibbs energy $\Delta \mathrm{G}^{\circ}{ }_{1}$ for the first stage of the formation of the enzyme-substrate complex. It is worth noting that the value of $\Delta \mathrm{G}^{\circ}{ }_{1,298}$ (ranging from -7.0 to $-7.4 \mathrm{kcal} / \mathrm{mol}$ ) is similar for both damaged and intact DNA, indicating that the interaction of the enzyme with DNA is energetically favorable.

The thermodynamic parameters of the first stage obtained for G-DNA, F-DNA, and DHU-DNA indicate that the initial stage of interaction (up to $10 \mathrm{~ms}$ ) between Endo VIII and DNA is identical for all of the DNA duplexes. No specific contacts with the damaged nucleotide take place at the stage of primary binding. The recognition of the damaged nucleotide occurs later, upon its eversion from the DNA helix and incorporation of the Gln69-Leu70-Tyr71 triad into the helix. Nevertheless, it has been established [9] that Endo VIII utilizes Leu70 as a "sensor" of damaged nucleotides and that its intercalation into the duplex structure takes place at early stages of specific enzyme-substrate interaction. Therefore, one can assume that an increase 
Table 5. Thermodynamic parameters of interaction of Endo VIII with DNA

\begin{tabular}{|c|c|c|c|c|c|}
\hline $\begin{array}{c}\text { DNA } \\
\text { substrate }\end{array}$ & $\begin{array}{l}\text { Stage } \\
\text { No }\end{array}$ & $\begin{array}{c}\Delta \mathrm{H}_{\mathrm{i}}^{\circ} \\
\mathrm{kcal} / \mathrm{mol}\end{array}$ & $\begin{array}{c}\Delta \mathrm{S}_{\mathrm{i}}^{\circ} \\
\mathrm{cal} /(\mathrm{mol} \times \mathrm{K})\end{array}$ & $\begin{array}{c}\Delta \mathrm{G}^{\mathrm{o}}{ }_{\mathrm{i}, 298} \\
\mathrm{kcal} / \mathrm{mol}\end{array}$ & Stage description ${ }^{\mathrm{a}}$ \\
\hline $\mathrm{G} / \mathrm{tC}^{\mathrm{O}}$ & 1 & $-3.6 \pm 0.9$ & $12 \pm 3$ & -7.2 & $\begin{array}{l}\text { Primary binding, attempt at incorporation of Leu70 resi- } \\
\text { due, increase in the polarity of the } \mathrm{tC}^{\mathrm{O}} \text { environment }\end{array}$ \\
\hline \multirow[t]{3}{*}{$\mathrm{F} / \mathrm{tC}^{\mathrm{O}}$} & 1 & $-2.8 \pm 0.3$ & $16 \pm 1$ & -7.4 & $\begin{array}{c}\text { Primary binding, intercalation of Leu70, increase in the } \\
\text { polarity of the } \mathrm{tC}^{\mathrm{O}} \text { environment }\end{array}$ \\
\hline & 2 & $15 \pm 3$ & $47 \pm 9$ & 0.8 & $\begin{array}{l}\text { Bending of the double helix, increase in the polarity of the } \\
\qquad \mathrm{tC}^{\mathrm{O}} \text { environment }\end{array}$ \\
\hline & $\sum_{i=1}^{i=2}$ & $12.2 \pm 3.3$ & $60 \pm 10$ & -6.6 & \\
\hline \multirow[t]{6}{*}{$\mathrm{DHU} / \mathrm{tC}^{\mathrm{O}}$} & 1 & $-0.7 \pm 0.1$ & $21.3 \pm 0.4$ & -7.0 & $\begin{array}{c}\text { Primary binding, increase in the polarity of the } \mathrm{tC}^{\mathrm{O}} \\
\text { environment }\end{array}$ \\
\hline & 2 & $1.0 \pm 0.2$ & $5.5 \pm 0.6$ & -0.65 & $\begin{array}{l}\text { Bending of the double helix, increase in the polarity of the } \\
\qquad \mathrm{tC}^{\mathrm{O}} \text { environment }\end{array}$ \\
\hline & 3 & $3.9 \pm 0.7$ & $17 \pm 2$ & -1.1 & $\begin{array}{l}\text { Formation of a catalytic complex, decrease in the polarity } \\
\text { of the } \mathrm{tC}^{\mathrm{O}} \text { environment }\end{array}$ \\
\hline & $\sum_{i=1}^{i=3}$ & 4.2 & 43.8 & -8.75 & \\
\hline & $4^{\mathrm{b}}$ & $14.4 \pm 0.1$ & $-12.4 \pm 0.5$ & 18 & Catalysis, increase in the polarity of the $\mathrm{tC}^{\mathrm{O}}$ environment \\
\hline & 5 & $-4.5 \pm 0.6$ & $5 \pm 2$ & -6.2 & $\begin{array}{l}\text { Formation of a complex with the reaction product, } \\
\text { increase in the polarity of the } \mathrm{tC}^{\mathrm{O}} \text { environment }\end{array}$ \\
\hline
\end{tabular}

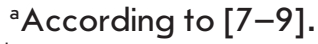

${ }^{b}$ Parameters calculated using the Eyring equation (2).

in the $\mathrm{tC}^{\mathrm{O}}$ fluorescence intensity at the initial regions of all kinetic curves reflects local conformational changes in the DNA duplex upon wedging of the Leu70 residue into the DNA helix.

The thermodynamic analysis of the second stage of recruitment of Endo VIII to DNA duplexes observed in the case of $\mathrm{F}$ - and DHU-containing duplexes revealed a degree of difference. A positive $\Delta \mathrm{G}^{\circ}{ }_{2}{ }_{298}$ value in the case of F-DNA indicates that the process is unfavorable and does not appear to take place at low temperatures. In the case of the DHU-containing substrate, the second stage of enzyme-substrate complex formation is energetically neutral; the $\Delta \mathrm{G}^{\circ}{ }_{2}{ }_{298}$ value is equal to -0.65 $\mathrm{kcal} / \mathrm{mol}$. This stage is accompanied by an increase in $\Delta \mathrm{H}^{\circ}$ and $\Delta \mathrm{S}^{\circ}$ for both DNA duplexes. According to previously obtained data, at this stage, duplex bending occurs, which should be accompanied by the insertion of the damaged nucleotide into the active center of the enzyme and complete incorporation of all residues of the Gln69-Leu70-Tyr71 triad into the DNA helix [8].

Final adjustment of the active center structure occurs for the transition to the catalytic stage at the third stage of interaction between Endo VIII and the DHU substrate, which precedes the catalytic reaction. The significant increase in entropy observed at this stage is most likely due to the dissolving of polar groups in the region of the enzyme-DNA contact, as well as the removal of water molecules from the grooves of the DNA substrate. A positive change in the enthalpy $\Delta \mathrm{H}^{\circ}$ indicates energy costs in obtaining a catalytically active conformation. This is followed by the irreversible catalytic stage (stage 4), which includes hydrolysis of the N-glycosidic bond of the damaged nucleotide and formation of a gap in the sugar-phosphate backbone of the DNA at the 3'- and 5'-sides from the damaged nucleotide. The catalytic stage is accompanied by a large expenditure of energy, as indicated by the positive values of $\Delta \mathrm{G}^{\mathrm{o}, \ddagger}{ }_{298}=18.0 \mathrm{kcal} / \mathrm{mol}$ and $\Delta \mathrm{H}^{\mathrm{o}, \ddagger}=14.4 \mathrm{kcal} / \mathrm{mol}$. The final stage of interaction between Endo VIII and a DHU-containing substrate is the dissociation of the enzyme complex from the product. It should be noted that $\Delta \mathrm{G}^{\circ}{ }_{298}(-6.2 \mathrm{kcal} / \mathrm{mol})$ of this stage has a value similar to that of $\Delta \mathrm{G}^{\mathrm{o}}{ }_{298}$ for the primary DNA binding stage $(-7.0$ to $-7.4 \mathrm{kcal} / \mathrm{mol})$.

\section{CONCLUSION}

The changes in the fluorescence intensity of 1,3-diaza2-oxophenoxazine in the $\mathrm{X}: \mathrm{tC}^{\mathrm{O}}$ pair $(\mathrm{X}=\mathrm{G}, \mathrm{F}, \mathrm{DHU})$ were recorded for all of the Endo VIII DNA glycosylase substrates used in the study. It has been shown that 
the first phase of $\mathrm{tC}^{\mathrm{O}}$ fluorescence intensity growth is characteristic of the kinetic curves obtained for all of the substrates. According to the thermodynamic parameters obtained, this stage reflects a similar stage of the primary binding of Endo VIII to DNA. According to [7-9], this stage presents closure of the enzyme domains and an attempt to incorporate Leu70 into the DNA helix. The second phase of growth in fluorescence intensity is recorded only for DNA duplexes carrying the damaged nucleotide F or DHU. This change corresponds to the stage of second enzyme-substrate complex formation. The insertion of the damaged nucleotide into the active center of Endo VIII and incorporation of the amino acid residues of Endo VIII into the DNA double helix is likely to occur at this stage. For DHU-DNA, this stage lasts up to $1 \mathrm{~s}$. It is worth noting that both enthalpy and entropy increase in this case. However, the change in the Gibbs energy $\Delta \mathrm{G}^{\circ}{ }_{i, 298}$ is close to zero ( 0.8 and $-0.65 \mathrm{kcal} / \mathrm{mol}$ for F-DNA and DHU-DNA, respectively) at this stage. Hence, the energy costs of changing the structure of the enzyme and DNA substrate molecules are compensated by the increase in the entropy of the system. The kinetic curves
(Fig. 5) obtained for the DHU-containing duplex show that the two phases of growth in the $\mathrm{tC}^{\mathrm{O}}$ fluorescence intensity are followed by a phase of decrease, reflecting the formation of the third enzyme-substrate complex. The final verification of the structure of the damaged nucleotide and formation of a catalytically active complex is carried out at this stage. In this case, the fluorescence intensity of $\mathrm{tC}^{\mathrm{O}}$ is minimal, indicating the formation of the most hydrophobic environment for the fluorophore group. Also, this stage is accompanied by an increase in entropy, probably indicating the removal of water molecules from the enzyme-substrate contact region and, consequently, compaction of the enzymesubstrate complex. The thermodynamic parameter values of the fast stages of interaction between Endo VIII and DNA are consistent with previously obtained data on the mechanism of recognition and conversion of the specific site by the enzyme [7-9]. The relative changes in the thermodynamic parameters of individual fast stages of the enzymatic process catalyzed by Endo VIII DNA glycosylase are in agreement with the values previously obtained by us for other DNA glycosylases, such as Fpg [19], hOGG1 [20], and Nth [22].
REFERENCES

1. Jiang D., Hatahet Z., Melamede R.J., Kow Y.W., Wallace S.S. // J. Biol. Chem. 1997. V. 272. № 51. P. 32230-32239.

2. Melamede R.J., Hatahet Z., Kow Y.W., Ide H., Wallace S.S. // Biochemistry. 1994. V. 33. № 5. P. 1255-1264.

3. Burgess S., Jaruga P., Dodson M.L., Dizdaroglu M., Lloyd R.S. // J. Biol. Chem. 2002. V. 277. № 25. P. 2938-2944.

4. Kropachev K.Y., Zharkov D.O., Grollman A.P. // Biochemistry. 2006. V. 45. P. 12039-12049.

5. Golan G., Zharkov D.O., Feinberg H., Fernandes A.S., Zaika E.I., Kycia J.H., Grollman A.P., Shoham G. // Nucl. Acids Res. 2005. V. 33. № 15. P. 5006-5016.

6. Zharkov D.O., Golan G., Gilboa R., Fernandes A.S., Gerchman S.E., Kycia J.H., Rieger R.A., Grollman A.P., Shoham G. // EMBO J. 2002. V. 21. № 4. P. 789-800.

7. Kuznetsov N.A., Koval V.V., Zharkov D.O., Fedorova O.S. // DNA Repair. 2012. V. 11. № 11. P. 884-891.

8. Kuznetsova A.A., Kuznetsov N.A., Vorobjev Y.N., Barthes N.P.F., Michel B.Y., Burger A., Fedorova O.S. // PLoS One. 2014. V. 9. № 6. P. e100007.

9. Kladova O.A., Kuznetsova A.A., Fedorova O.S., Kuznetsov N.A. // Genes (Basel). 2017. V. 8. № 5. P. 1-13.

10. Fasman G.D. Handbook of Biochemistry and Molecular Biology. 3rd Ed.// Cleveland: CRC Press, 1975.

11. Gill S.C., von Hippel P.H. // Anal. Biochem. 1989. V. 182. P. 319-326

12. Kuzmic P. // Anal. Biochem. 1996. V. 237. P. 260-273.
13. Yakovlev D.A., Kuznetsova A.A., Fedorova O.S.,

Kuznetsov N.A. // Acta Naturae. 2017. V. 9. № 1. P. 88-98.

14. Kuznetsova A.A., Iakovlev D.A., Misovets I.V., Ishchenko

A.A., Saparbaev M.K., Kuznetsov N.A., Fedorova O.S. //

Mol. Biosyst. 2017. V. 13. № 12. P. 2638-2649.

15. Kuznetsov N.A., Kiryutin A.S., Kuznetsova A.A., Panov M.S., Barsukova M.O., Yurkovskaya A.V., Fedorova O.S. // J. Biomol. Struct. Dyn. 2017. V. 35. № 5. P. 950-967.

16. Miroshnikova A.D., Kuznetsova A.A., Vorobjev Y.N.,

Kuznetsov N.A., Fedorova O.S. // Mol. BioSyst. 2016. V. 12. № 5. P. 1527-1539.

17. Atkins P., Paula J. Atkins' Physical Chemistry. 8th Ed.// Oxford university press, 2006.

18. Ragone R., Colonna G., Ambrosone L. // J. Phys. Chem. 1995. V. 99. № 34. P. 13050.

19. Kuznetsov N.A., Vorobjev Y.N., Krasnoperov L.N., Fedorova O.S. // Nucl. Acids Res. 2012. V. 40. № 15. P. 7384-7392.

20. Kuznetsov N.A., Kuznetsova A.A., Vorobjev Y.N., Krasnoperov L.N., Fedorova O.S. // PLoS One. 2014. V. 9. № 6. P. e98495.

21. Miroshnikova A.D., Kuznetsova A.A., Kuznetsov N.A., Fedorova O.S. // Acta Naturae. 2016. V. 8. № 1. P. 103-110. 22. Kladova O.A., Krasnoperov L.N., Kuznetsov N.A., Fedorova O.S. // Genes (Basel). 2018. V. 9. № 4. E190.

23. Kuznetsov N.A., Fedorova O.S. // Biochem. 2016. V. 81. № 10. P. 1136-1152. 